\title{
Análisis interpretativo del impacto del turismo en el patrimonio cultural artesanal. Tepoztlán, México
}

\section{Interpretative analysis of the impact of tourism on traditional cultural heritage. Tepoztlan, Mexico}

Oliver Adair Saldaña-Ortega, Universidad Autónoma del Estado de México, México.

realde14blues@gmail.com

Rocío del Carmen Serrano-Barquín (iD, Universidad Autónoma del Estado de México, México. rocioserba@yahoo.com.mx

María José Pastor-Alfonso, Universidad de Alicante, España. josefa.pastor@ua.es

Yanelli Daniela Palmas-Castrejón (iD, Universidad Autónoma del Estado de México, México. hashir04@hotmail.com

\section{RESUMEN}

En la actualidad el turismo, como promotor y potenciador de cambios socioculturales, influye progresivamente en la construcción de la cotidianidad de las poblaciones humanas, siendo especialmente visible en aquellos nichos laborales que interactúan con la otredad turística. Tal es el caso de la actividad artesanal, constantemente resignificada desde los paradigmas culturales propios del artesano, y las tendencias demandadas desde el comprador. El presente artículo tiene como objetivo exponer los impactos de la actividad turística en el patrimonio cultural artesanal de Tepoztlán, México, desde una perspectiva interpretativa. Para ello se recurrió a una investigación etnográfica de corte cualitativo, que permitiese conocer los impactos existentes en este patrimonio desde la percepción de los distintos agentes locales. En este contexto, se reconoce el rol multifacético del turismo en la construcción de la actividad artesanal y su influencia en la artesanía misma, tanto en las formas de comercio y la situación económica del artesanado, como en algunos procesos de producción, vislumbrándose como una oportunidad potencial de desarrollo local o un problema recurrente según los matices de cada agente social.

Palabras clave: Impactos del turismo; patrimonio cultural; artesanía; percepción; agentes sociales 


\section{ABSTRACT}

As a promoter and enhancer of socio-cultural changes tourism is progressively influencing the construction of the daily life of human populations. This is particularly noticeable in those labor niches that interact more directly with the variability of tourism. Such is the case of artisanal activity in constant resignification from the artisan's own cultural paradigms and the buyer's demand trends. This article seeks to describe the impacts of tourism on the existing cultural heritage in Tepoztlán, Mexico from an interpretative perspective. To accomplish this, an ethnographic research method has been used, which provides information about the existing impacts on this heritage from the perspective of the different local agents. In this context, the multifaceted role of tourism is recognized in the construction of the artisanal activity and the influence on the craft itself, both on the forms of commerce and the economic situation of artisans and on certain production processes, seen as a potential opportunity for local development or a recurrent problem depending on the characteristics of each social agent.

Keywords: Impacts of tourism; cultural heritage; crafts; perception; social agents

\section{INTRODUCCIÓN}

El turismo, como práctica social, repercute progresivamente en la configuración cultural de las comunidades contemporáneas, tanto en su construcción simbólica e identitaria, como en su desarrollo económico (Fuller, 2008; Izaguirre, 2010; Weaver, 2011). Para el caso de la actividad artesanal, ésta se establece dentro del turismo como atractivo cultural y producto comercial, a la vez que se va resignificando según los presupuestos locales y los imaginarios turísticos (Popelka, 1991; Novelo, 2003; Fuller, 2008).

A nivel académico, existen varios estudios que analizan la importancia comercial y simbólica de la artesanía dentro de la actividad turística (Forstner, 2013; luva y Ciliane, 2015) donde ésta, más allá de reducirse a la condición de mercancía para el turismo, presenta un fuerte trasfondo sociocultural e histórico, recogiendo y renovando técnicas, procesos y significados propios de las comunidades que las elaboran, especialmente en aquellas con legado étnico (Morales y Quintal, 1993; Del Carpio, 2012), a la vez que se adhieren al dinamismo del turismo, reconfigurándose entre los significados atribuidos desde la propia cultura local con aquellos asimilados desde la demanda de la otredad turística.

De este modo, el turismo se vincula a los cambios estructurales de la comunidad artesanal dentro de su propio contexto social, situación que se ve reflejada en los modos de producción, comercialización y reventa de un producto originalmente utilitario condicionado a la demanda del turismo, convirtiéndose así en un recuerdo de viaje y parte del atractivo turístico, sin que esto necesariamente desvirtúe su función original dentro de la sociedad productora (Monterrubio, 2011). Las artesanías se consideran una evidencia de la experiencia del viaje, se comercializan para el consumo turístico, "su valor de uso pasa a adoptar un valor de cambio" y se transforman para "satisfacer las expectativas y deseos de los turistas" (Monterrubio, 2018: 57).

En este sentido, uno de los principales mecanismos para la permanencia de la producción artesanal en el mundo contemporáneo se encuentra en el comercio (valor económico) 
que, si bien se nutre del valor cultural y la identidad de las comunidades locales, tiene como fin primario la generación de un capital que permita al artesanado satisfacer sus necesidades básicas y mantenerse competitivo dentro del mercado local (Turok, 1988; Morales y Quintal, 1993; Zorrilla, 2004; Arroyo, 2006; Núñez, 2017). Así mismo, en la mayoría de los casos, la artesanía surge como un elemento propio de la cotidianidad de las sociedades, siendo desplazada paulatinamente por los avances industriales y tecnológicos que la sustituyen en cuanto a técnicas, costes de producción o practicidad, o bien se va reacondicionando como un objeto ornamental por encima de su funcionalidad (Zorrilla, 2004). Claro ejemplo se encuentra en los juguetes y vestimentas tradicionales que, pese a mantenerse vigentes en ciertos nichos de la población en cuanto a su función original, a nivel general han sido relegados por los productos en masa, pasando de ser objetos de uso común a productos estéticos y souvenirs para el visitante (Monterrubio, 2011).

En este tenor, desde los presupuestos teóricos del desarrollo local se contempla a la artesanía como uno de los pilares para la oferta del turismo cultural desde un enfoque comunitario o rural, (Rivera, Alberti, Vázquez y Mendoza, 2008; Campaña, Molina y Romero, 2015) a través de la generación de colectivos y empresas familiares que promuevan el desarrollo mediante la participación integral de la población, enfatizando en la conservación y fomento de las prácticas locales.

Bajo esta pauta, se reconoce el valor cultural que tiene la artesanía para las comunidades productoras, fungiendo como un receptáculo para la transmisión de sus tradiciones, identidad y cosmovisiones, reforzando de esta manera el vínculo entre el valor patrimonial, atribuido implícitamente por la propia comunidad, y el valor económico otorgado para su comercialización (Turok, 1988; Del Carpio, 2012; Sales, 2013).

Para el caso de México, destaca el estudio comparativo sobre innovación y competitividad en el sector artesanal de Jiménez, Domínguez y Martínez (2009), que considera grupos artesanos de ocho diferentes estados. En este análisis se llega a la conclusión de que, si bien la innovación es una constante dentro de la actividad, ésta se presenta exclusivamente en el proceso de producción, pero muy esporádicamente en los modos de promoción y venta; sin embargo, se hace presente la importancia de la calidad del trabajo como factor determinante para la permanencia de la actividad dentro del mercado mexicano.

Así mismo autores como Del Carpio (2012) y Núñez (2015), enfatizan en las condiciones precarias de la actividad artesanal en México, así como los contrastes entre la artesanía, comúnmente señalada como un elemento patrimonial propio de la identidad cultural mexicana, y el artesano, relegado a la simple condición de fabricante que subsiste en el desempeño de una actividad económica difícilmente bien remunerada para el productor, y que es altamente explotada por revendedores en comunidades indígenas y rurales (Novelo, 2003; Del Carpio-Ovando y Freitag, 2013).

Tras lo expuesto, el presente artículo busca exponer cómo la actividad turística influye en la generación de impactos en el patrimonio cultural artesanal del pueblo de Tepoztlán, México. En este sentido, se analizan las percepciones de los distintos agentes sociales que participan en la construcción, promoción o permanencia de la actividad artesanal dentro de la comunidad respecto a la influencia del turismo en los distintos valores patrimoniales que engloba la artesanía tepozteca. 


\section{UBICACIÓN GEOGRÁFICA}

Según datos del Instituto Nacional para el Federalismo y el Desarrollo Municipal (INAFED, 2017), el municipio de Tepoztlán pertenece a la zona centrosur de México, limitando al norte con la Ciudad de México y al oeste con la ciudad de Cuernavaca, capital del Estado de Morelos (imagen 1). En términos generales, se reconoce como un municipio de carácter rural, donde destacan las actividades agrícolas y el comercio en las comunidades aledañas, además de la prestación de servicios turísticos en la cabecera municipal.

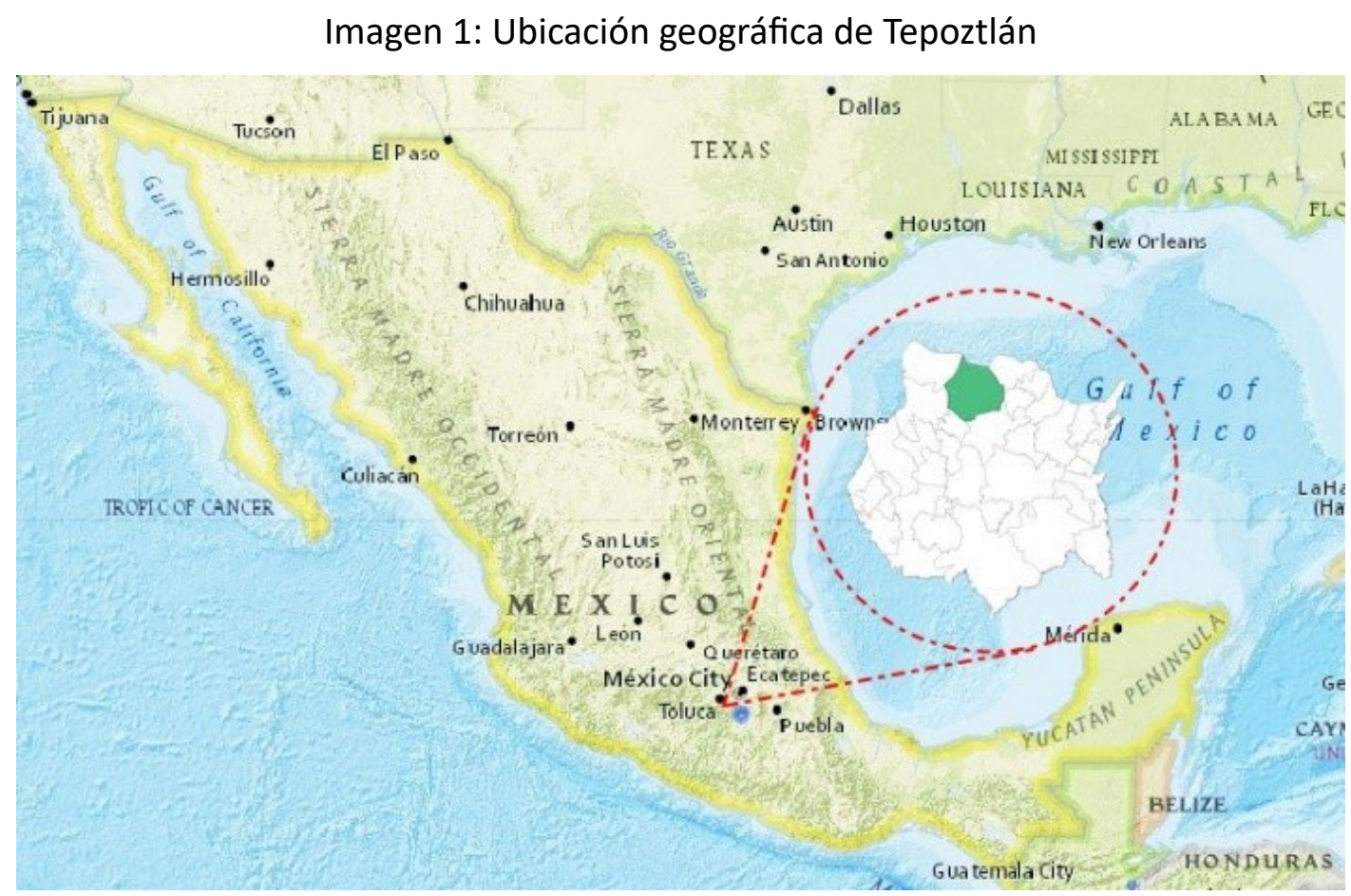

Fuente: Elaboración propia a partir de NatGeo mapmaker interactive.

De acuerdo con cifras recabadas por la Secretaría de Hacienda de Morelos a través del Consejo Estatal de Población (COESPO, 2018) el pueblo de Tepoztlán cuenta en la actualidad con 12,667 habitantes. Así mismo, se encuentra registrado dentro del programa federal "Pueblos Mágicos" (PPM), cuyo objetivo es la promoción turística y la conservación natural y cultural de las comunidades insertas, por lo que la gestión de esta actividad queda sujeta a los objetivos y reglamentos estipulados a través de dicho programa.

Así mismo, entre los principales atractivos de la comunidad destacan el Cerro y la Pirámide del Tepozteco, el ex convento de la Natividad y el museo de arte prehispánico Carlos Pellicer, además del mercado de artesanías y el mercado orgánico, así como los servicios de senderismo, acampado y rappel, entre otros.

Sin embargo, aunque el proyecto turístico que actualmente se está gestionando para la comunidad va encaminado al turismo natural y cultural, el historial del PPM ha sido de un turismo de masas, priorizando el incremento del flujo turístico por encima de una planeación sustentable, condición que ha llevado a la proliferación de un perfil de turista menos consciente 
de su huella en el destino y una consecuente saturación comercial, tal como se observa en Alvarado (2015), donde se señalan los contrastes entre los postulados teóricos del PPM y su ejecución en la comunidad.

Cabe señalar que este exceso en la afluencia turística ha permeado en el tejido social de la comunidad tepozteca, influyendo a nivel cultural y económico en su cotidianidad, efecto que se refleja en la actividad artesanal, tanto a nivel técnico como comercial. Por esta razón, resulta relevante hacer un análisis de los impactos que la actividad turística ha tenido en la realidad sociocultural y económica del artesanado tepozteco, por lo que se considera pertinente presentar el siguiente apartado metodológico en función de los objetivos de este artículo.

\section{METODOLOGÍA}

Dado el carácter interpretativo de la presente investigación, se optó por un análisis de corte cualitativo sustentado en el método etnográfico (Muecke, 2003; Hammersley, 2005; Murillo y Martínez, 2010; Govea y Vargas, 2011), que permitió conocer las percepciones y supuestos de los diferentes agentes sociales respecto a la construcción del patrimonio cultural artesanal tepozteco y el impacto que la actividad turística tiene en éste. Se analizan las experiencias de los individuos que permitan un acercamiento al conocimiento cotidiano (Angrosino, 2012).

Para ello se recurrió a la observación participante y las entrevistas semiestructuradas a profundidad, buscando conocer los elementos que componen el patrimonio artesanal local; los procesos de inserción de la artesanía en la cotidianidad del pueblo de Tepoztlán; y las formas de producción, comercio e interacción con el turismo. En este sentido, tal como señala Robles (2011), este tipo de entrevistas, propias del método cualitativo, no buscan respaldarse en una representación netamente estadística, sino en el análisis profundo y minucioso de la información obtenida por cada entrevistado, por lo que la selección y cantidad de entrevistados se determinó a través del proceso etnográfico. Así, la entrevista giró en función de dos categorías de análisis:

1. Composición del patrimonio cultural artesanal de Tepoztlán: mediante esta categoría se buscó conocer cuáles son las artesanías que más representativas para la comunidad tepozteca; así como sus modos de producción e inserción en la dinámica social cotidiana.

2. Impactos del turismo en la artesanía local: mediante esta categoría se buscó vislumbrar la percepción actual de los agentes respecto a la influencia que tiene la actividad turística con relación a los valores patrimoniales insertos en la artesanía, en los sentidos de tergiversación, resignificación, sustentabilidad y permanencia.

Bajo esta pauta, para la selección de los informantes clave se consideraron aquellos agentes sociales relacionados con la gestión del turismo en la comunidad y la actividad artesanal, tanto al nivel de la producción como en los sentidos del comercio, regulación, promoción o competencia, los cuales fueron divididos en cinco campos, de acuerdo con sus características, para facilitar el análisis de la información: 
$A=\operatorname{artesanos}^{1,2}$

$\mathrm{C}=$ comerciantes de artesanías

$\mathrm{FL}=$ funcionarios locales (en este caso, de las áreas de turismo, económica y desarrollo)

PST $=$ prestadores de servicios turísticos

PrTD = promotores de turismo y desarrollo local (sector privado, ONG y particulares)

Para el caso del sector artesanal, se recurrió a las visitas particulares y la búsqueda de información directa dentro de la localidad, derivando en un efecto de bola de nieve que optimizó la localización de algunos de los principales artesanos de la zona centro de Tepoztlán y de las localidades vecinas, además de otros agentes menos visibles. Así mismo, algunas autoridades locales relacionadas con el turismo y la economía facilitaron el acceso a ciertos nichos de artesanos y comerciantes de la zona del mercado artesanal. De este modo, se realizaron un total de 35 entrevistas, de las que se rescatan algunos extractos, a modo de narrativa y bajo el esquema del anonimato, con el objetivo de apoyar la información presentada.

Paralelamente, y considerando que el patrimonio artesanal varía de acuerdo con los presupuestos ideológicos, el contexto y los intereses de cada uno de los agentes sociales; se determinó la realización de un análisis según aquellos elementos que configuran el valor patrimonial artesanal, por lo cual se presenta el siguiente modelo y su respectiva explicación con base en la investigación documental realizada:

Figura 1: Configuración del valor patrimonial artesanal

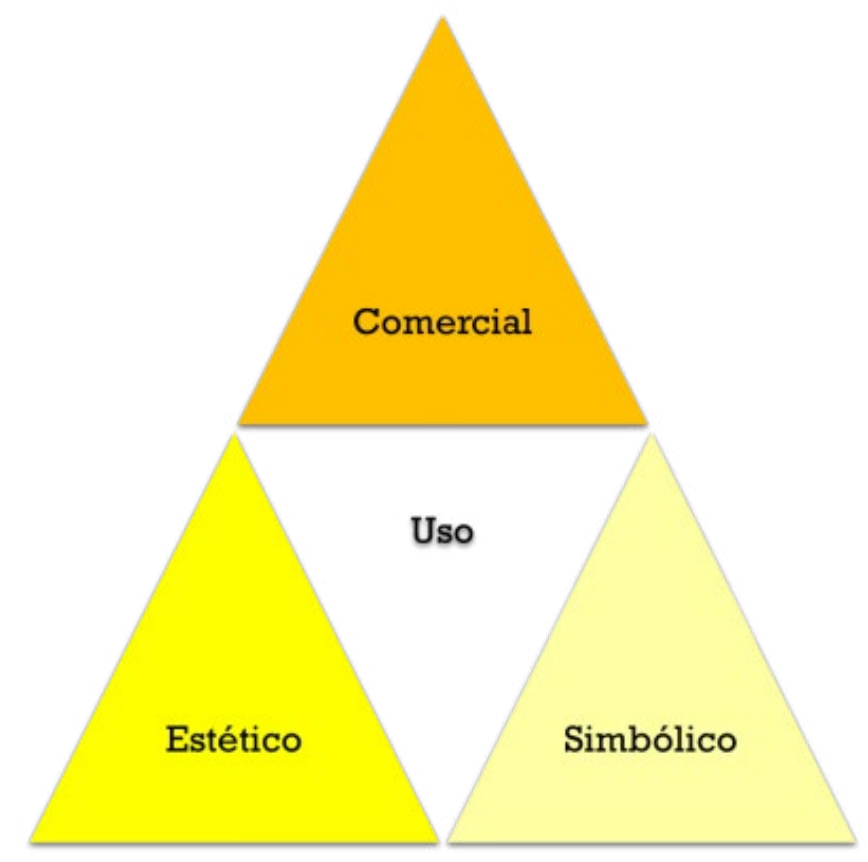

Fuente: Elaboración propia.

1. Entiéndase como artesano al individuo que interviene directamente en el proceso de producción artesanal, tanto aquel que se dedica exclusivamente a la producción, como aquel que además interactúa con el turismo a través del comercio. Por otro lado, la categoría comerciante de artesanías refiere al grupo de individuos que se dedican a la compra-venta de artesanías sin que éstos participen en la producción.

2. Las siglas presentadas se emplean como referencia para los fragmentos de entrevistas del apartado $\mathbf{V}$. RESULTADOS. 
1. Valor de uso: refiere al fin utilitario de la artesanía; tanto a su génesis histórica, comúnmente atribuida a la generación de herramientas y la satisfacción de necesidades primarias, como la vestimenta (Dittmer, 1960; Zorrila, 2004; Aguilar, 2015); hasta su permanencia y supervivencia en la cotidianidad actual, en una constante resignificación entre lo tradicional y lo moderno; es decir, el modo en que las artesanías se insertan y se viven dentro del flujo de las sociedades contemporáneas (Novelo, 2002; Fuller, 2008; Del Carpio y Freitag, 2013; Freitag, 2014).

2. Valor simbólico: hace referencia al qué es y qué significa la artesanía dentro de un contexto determinado; es decir, los signos y significados atribuidos a las piezas artesanales a través del conocimiento heredado de generación en generación, la identidad cultural local, y la percepción de la realidad desde los presupuestos ideológicos del artesanado (Turok, 1988; Mordó, 2004; Fuller, 2008; Oliva, 2009).

3. Valor estético: responde al contenido artístico implícito en cada pieza artesanal (Freitag, 2014; Aguilar, 2015); desde la creatividad e imaginario del artesano previo al inicio del trabajo; hasta la habilidad técnica empleada durante el proceso de producción y la calidad artística del producto final.

4. Valor comercial: adjudicado al oficio artesanal como actividad intrínsecamente económica, se manifiesta como la proporción ganancia-coste en la producción de piezas artesanales, y cómo éstas se incorporan a los flujos y demandas del mercado contemporáneo, especialmente en el marco de la actividad turística, donde además se atribuye a significados de atractivo y producto turístico con alto valor cultural, a la vez que se sujeta a una lucha de competencia constante con otros productos con la calidad de souvenirs (Mordó, 2004; Fuller, 2008).

Finalmente, para una mejor comprensión de los resultados, se optó por dividirlos en dos secciones acordes a las categorías de análisis anteriormente señaladas: la primera, haciendo un análisis descriptivo de la composición del patrimonio cultural artesanal tepozteco; y la segunda, homologando los vínculos existentes entre los agentes sociales, y su percepción respecto a la influencia del turismo dentro del patrimonio cultural artesanal.

\section{RESULTADOS}

\subsection{Composición del patrimonio cultural artesanal de Tepoztlán}

En el caso de Tepoztlán, a nivel institucional los proyectos relacionados con la promoción, exportación e incentivación del sector artesanal están a cargo del Departamento de Desarrollo Económico, quien considera que la importancia de la artesanía para la actividad turística radica en su valor comercial, al permitir la permanencia de estos elementos en la localidad, a la vez que aporta un añadido cultural al destino, donde adquieren la condición de producto turístico; sin embargo, más allá de la percepción institucional, a través de las entrevistas se pudo corroborar que muchas de las artesanías locales poseen un trasfondo cultural para la localidad, no sólo como elemento para el desarrollo turístico, sino como parte de sus tradiciones, mitos y cotidianidad, algunos de ellos vinculándose significativamente con la identidad tepozteca.

Así, de acuerdo con los actores sociales entrevistados, existe un amplio abanico de artesanías propias de la comunidad, entre las que destacan las casitas de pochote, el palo de 
Iluvia, el teponaztle, las velas aromáticas, la cera escamada, las piezas de bule, la escultura en injerto de aguacate y el traje de chínelo.

Desde el ámbito turístico, la artesanía más representativa para el artesanado de Tepoztlán es la casita de pochote, elaborada a partir de las espinas de la ceiba aesculifolia, comúnmente conocida como árbol de pochote, originalmente extraídas de la localidad, pero actualmente traídas de otros estados de México, situación que revela la existencia de redes de comercio de materia prima entre los artesanos y agricultores de dichas entidades, además de permitir la conservación de la flora local. Dentro de los motivos empleados para la elaboración de esta artesanía destacan las casitas tradicionales, los jacales y las representaciones de la pirámide del Tepozteco, presentadas comúnmente en el mercado artesanal; además de algunas esculturas de monumentos fantásticos, como castillos de estilo gótico o mudéjar, y arquitectónicos nacionales, como el Palacio de Bellas Artes o el Palacio de Cortés, que suelen ser elaboradas sobre pedido.

Otra artesanía muy presente en las zonas comerciales es el palo de lluvia (imagen 2), instrumento musical de percusión con forma de báculo, elaborado mediante el palo de bambú que en su interior contiene semillas que permiten simular el sonido del agua al voltearlo o agitarlo. Así mismo, pese a que este instrumento tiene sus orígenes en las tradiciones rituales prehispánicas bajo el nombre de ayochicahuaztli o na-hualcuahuitl (Martos, 2009; Garibay y Pilón, 2010), en la actualidad, tanto en la cotidianidad local, como desde la perspectiva del turista, obedece principalmente a un fin estético, ornamental y recreativo.

Finalmente, en cuanto a presencia en la zona comercial se encuentran las artesanías elaboradas mediante el bule o guaje (imagen 2), una especie de calabaza tradicionalmente empleada para la elaboración de recipientes y contenedores de agua que, gracias a su proliferación dentro de la zona agrícola local y la versatilidad con que se puede trabajar, es empleada en la generación de calaveras, esculturas, lámparas, elementos decorativos y recipientes para velas aromáticas, además de adaptarse a distintos tipos de acabado, como la quema, la pintura al óleo y el tallado, entre otros, siendo una de las artesanías locales mejor posicionada dentro de la zona turística.

Imagen 2: Palos de lluvia, calaveras de bule y casita de pochote
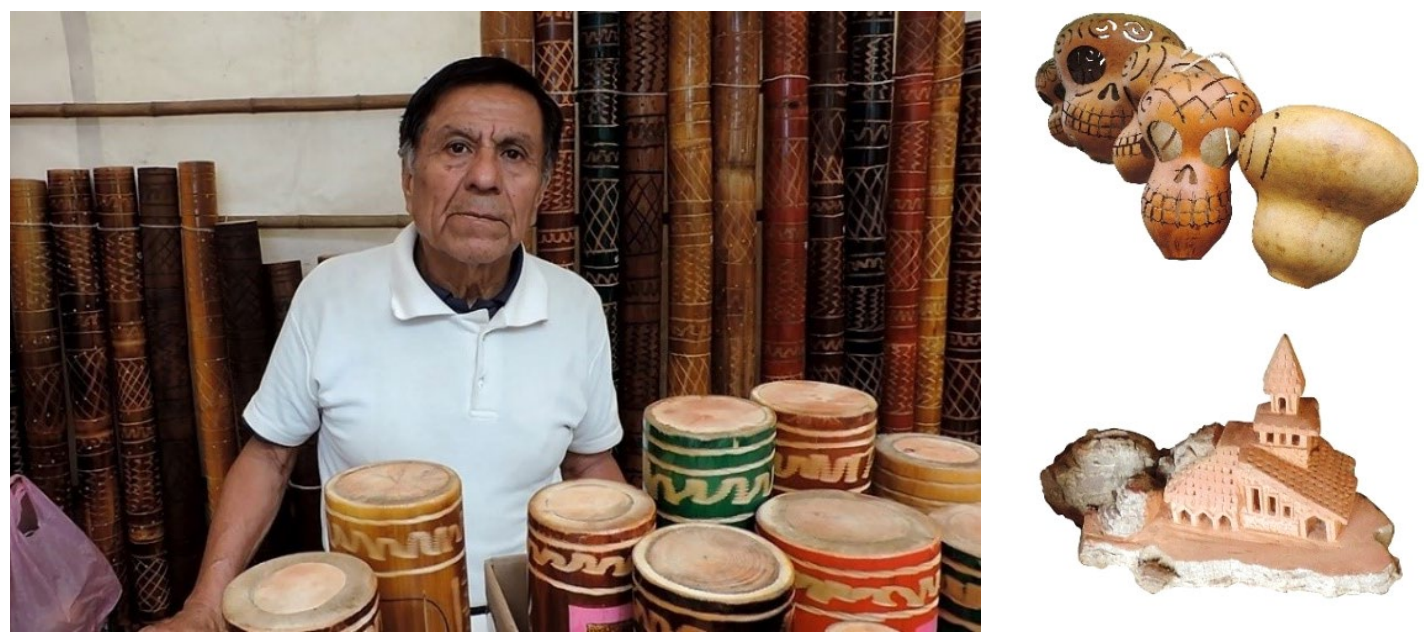

Autor: Saldaña, O. (2016).

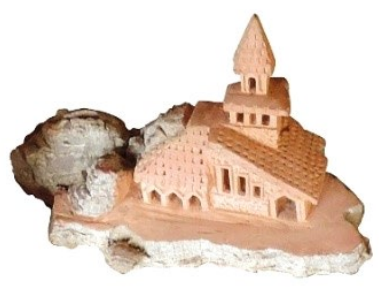


Análogamente, existen otras artesanías que no destacan tanto por su posicionamiento comercial sino por el valor simbólico atribuido a éstas. Tal es el caso del teponaztle, instrumento prehispánico de percusión elaborado de madera o bambú, de forma alargada y en cuyo centro sobresale una ranura hueca asimilando una " $\mathrm{H}$ ", que permite la generación del sonido al golpearla con dos varas a modo de baquetas, mismo que no sólo es un instrumento recurrente en la música y ritos prehispánicos, sino que además, junto a la chirimía, es el instrumento símbolo del dios Tepozteco y se encuentra comúnmente representado en la tradición oral de los mitos populares locales.

Otra artesanía que sobresale por su valor simbólico es el traje de chínelo (imagen 3), emblema del carnaval de Tepoztlán, principal evento turístico de la comunidad que, junto a los carnavales de Yautepec y Tlayacapan, conforman el llamado círculo del chínelo. El origen del traje de chínelo se atribuye a la comunidad de Tlayacapan; sin embargo, al ser adoptados por las comunidades de Yautepec y Tepoztlán, fueron adaptados a los estilos y presupuestos de cada comunidad, cambiando los materiales y colores, y matizando motivos locales como el cerro del Tepozteco y la pirámide dentro de la iconografía plasmada en el sombrero y volantón. En cuanto al valor comercial, el traje de chínelo, especialmente el sombrero, suele ser una pieza bien remunerada; no obstante, según los mismos artesanos y los funcionarios locales, éste es usualmente elaborado por y para el propio artesano, o en su defecto para miembros de su familia, por lo que su venta es esporádica y suele ser sobre pedido, o bien en exposiciones en el centro de la localidad. Así mismo, el traje del chínelo se mantiene arraigado como elemento patrimonial identitario para el pueblo de Tepoztlán pues, más allá de su uso dentro del carnaval, esta artesanía se concibe como uno de los elementos culturales más representativos de la localidad según sus propios habitantes, valorado a la par de los monumentos arqueológicos y naturales existentes en el área.

Imagen 3: Chínelos de Tepoztlán

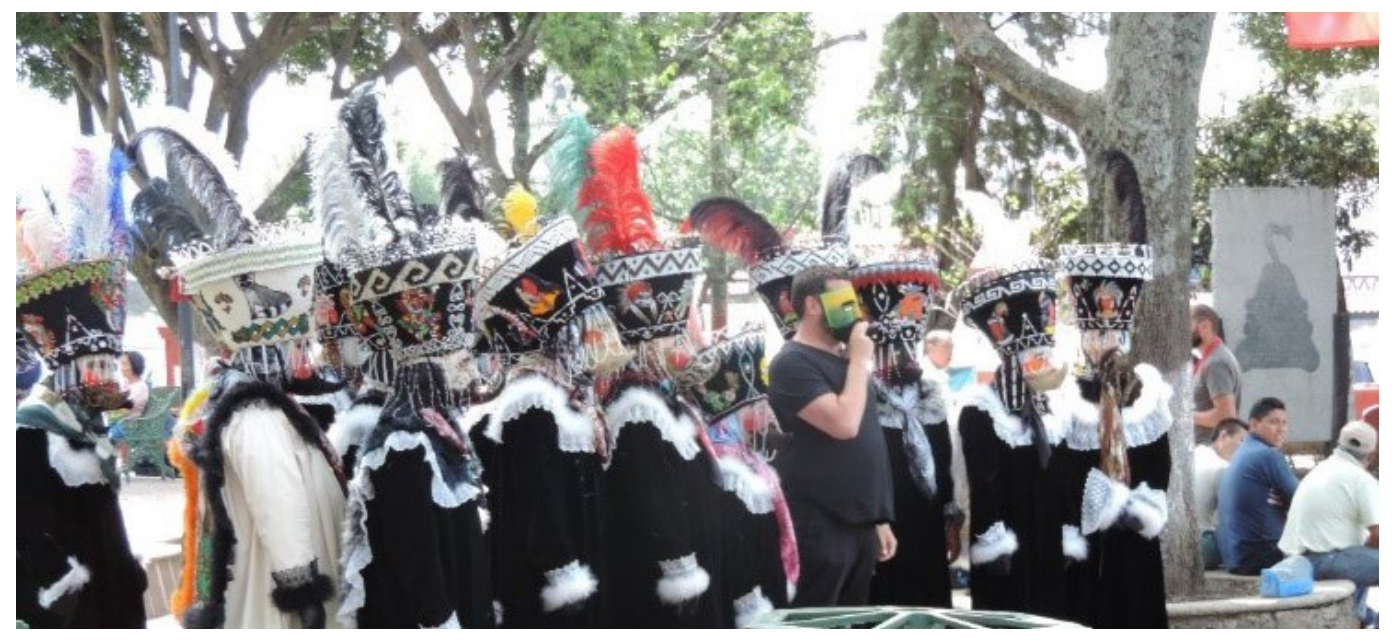

Autor: Saldaña, O. (2016).

Por último, artesanías como las velas aromáticas (imagen 4), la cera escamada y la escultura en injerto de aguacate, denotan menor presencia dentro de la localidad, siendo la cera escamada más propensa al trabajo sobre pedido para ceremonias litúrgicas que a la venta 
directa en el mercado artesanal. Este tipo de artesanías destacan por su valor de uso y estético, además de ser producidas con materiales orgánicos y desechables. En el caso de las velas aromáticas, la base es elaborada con cáscara de fruta (naranja, coco, piña), y los detalles retocados a mano con pétalos de flores silvestres, comercializándose principalmente en las ferias artesanales intermitentes de la localidad.

Con respecto a la cera escamada y las velas aromáticas, además de su función ornamental, suelen ser empleadas con fines rituales; la primera obedeciendo más a tradiciones litúrgicas, al predominar los motivos religiosos en las artesanías elaboradas mediante esta técnica (cirios pascuales, imágenes religiosas y motivos bautismales, por ejemplo); y la segunda, atribuida más ceremonias de relajación y sanación espiritual.

\section{Imagen 4: Velas aromáticas montadas en cáscara de naranja}
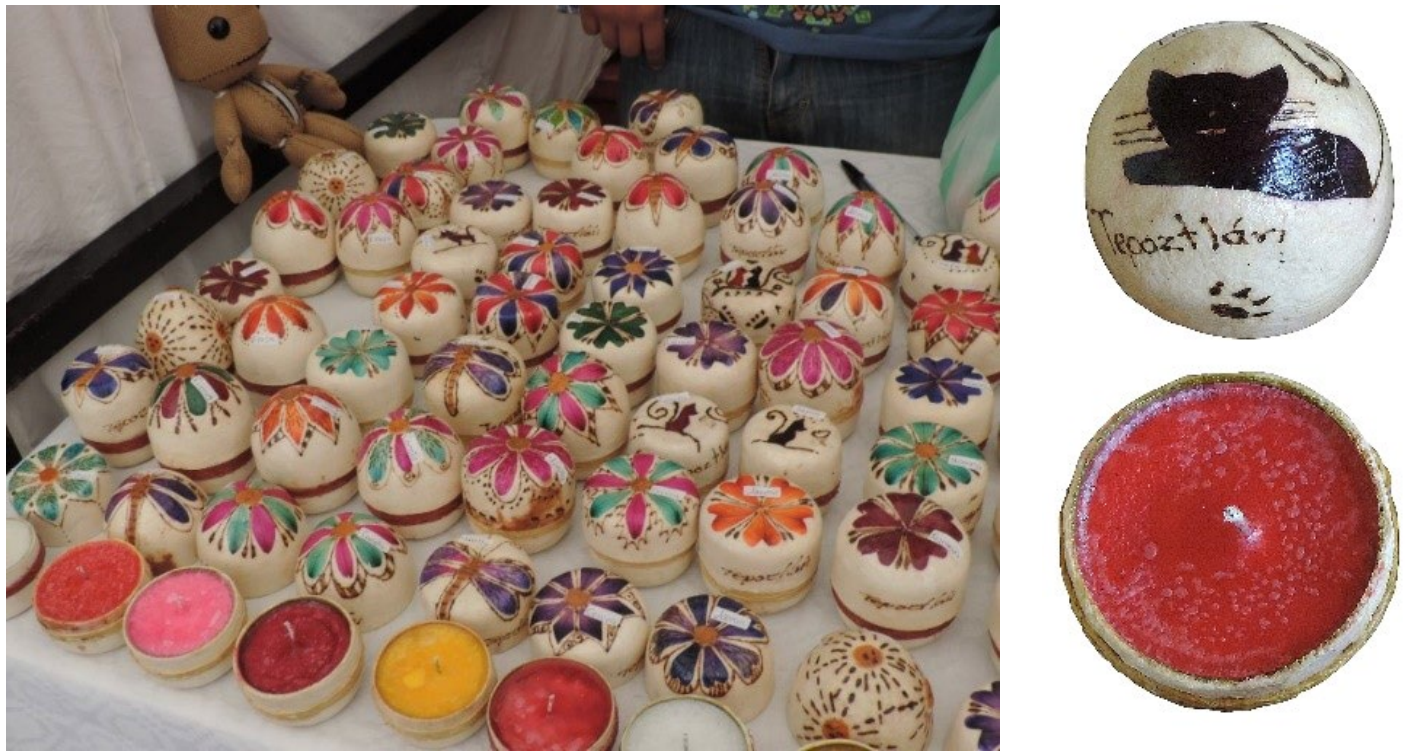

Autor: Saldaña, O. (2016)

Por su parte, la escultura en injerto de aguacate (imagen 5) es elaborada por artesanos que se dedican al trabajo sobre madera (casitas de pochote, palos de lluvia, teponaztles y otras artesanías de bambú), teniendo el carácter de artesanía complementaria dada la relativa dificultad para encontrar el material. Cabe señalar que el injerto es en realidad una plaga de la planta de aguacate, atribuida a los desechos de las palomas, que impide el desarrollo, crecimiento y brote del fruto, razón por la cual los productores de aguacate originalmente permitían al artesano extraerlas, pero que actualmente se vende como materia prima.

La gran ventaja es que no tenemos una artesanía basada en plantas nativas, realmente es muy poco el impacto que hay en el recurso natural, si acaso por las flores que se utilizan para adornar las velas. Incluso, usando el injerto de aguacate, se están cuidando las plantas, porque el injerto es como una plaga para el aguacate que no lo deja crecer; entonces, se cuidan las plantas y a la vez se aprovecha ese brote para hacer una artesanía (FL3). 
Imagen 5: Injerto de aguacate

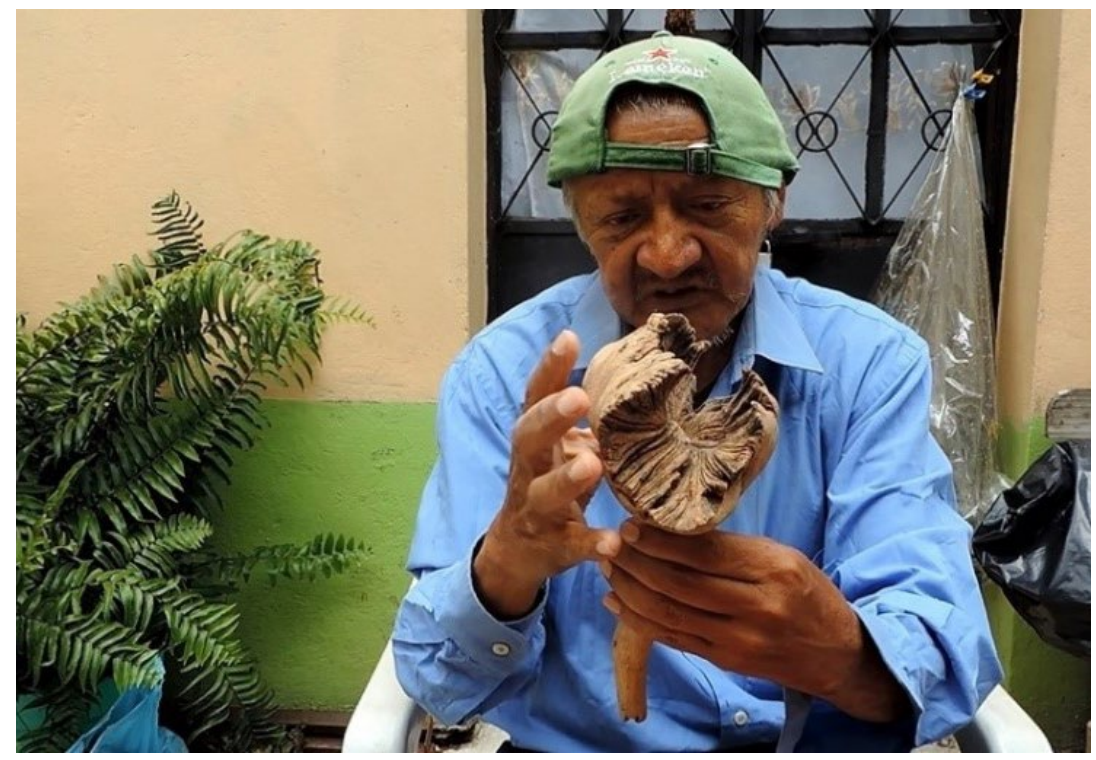

Autor: Saldaña, O. (2016).

De este modo, se reconoce la riqueza artesanal de la comunidad de Tepoztlán, encontrando en la madera y sus derivados la principal materia prima para la elaboración de las piezas, manteniendo además un fuerte apego en los simbolismos y tradiciones locales que se ven representados dentro de éstas. Sin embargo, como se mencionó anteriormente, la artesanía tepozteca se sujeta a la dinámica turística de la comunidad, por lo que es necesario analizar, además del valor cultural implícito dentro de estos objetos, los modos como se inserta y adapta a la cotidianidad social y económica local.

Por ello, mediante el uso del programa de análisis cualitativo, ATLAS.Ti, se generaron redes de co-ocurrencia que permitieron determinar las diferentes interacciones e interpretaciones de los entrevistados según la influencia atribuida al turismo en lo que respecta a los cambios y resignificaciones de los valores de uso, simbólico, estético y comercial insertos en el patrimonio artesanal tepozteco. Así mismo, se hace un cruce de variables entre algunos elementos que, desde la perspectiva de los propios entrevistados, condicionan la permanencia comercial y cultural de la artesanía dentro de la comunidad a corto y mediano plazo.

Como primer resultado del análisis, se observa un fuerte dominio del valor comercial como el principal motor de permanencia de la artesanía en la comunidad de Tepoztlán, siendo no solo el valor con mayor porcentaje de representación, sino que además se adjudica a los agentes sociales que interactúan de manera directa con el turista. Por su parte, el valor de uso y el valor estético sobresalen como elementos dominantes desde la perspectiva del artesanado, mientras que, para el resto de los agentes, no se vislumbran como factores determinantes. Finalmente, el valor de uso es el que presenta menor porcentaje de aparición a nivel general, corroborando el hecho de que la artesanía tepozteca se ha adherido a las dinámicas del turismo, resignificándose hacia los tenores del producto turístico por encima del de elemento utilitario para la cotidianidad local (Tabla 1). 
Tabla 1: Valores de Co-ocurrencia agentes sociales-valores culturales

\begin{tabular}{|c|c|c|c|c|c|c|}
\hline & Artesanos & Comerciantes & Funcionarios & $\begin{array}{c}\text { Prestadores } \\
\text { servicios }\end{array}$ & Promotores & TOTALES: \\
\hline Valor comercial & 28 & 14 & 3 & 12 & 2 & 59 \\
\hline Valor de uso & 9 & 1 & 0 & 1 & 3 & 14 \\
\hline Valor estético & 17 & 3 & 3 & 4 & 2 & 29 \\
\hline Valor simbólico & 22 & 4 & 3 & 10 & 3 & 42 \\
\hline
\end{tabular}

Fuente: Elaboración propia a partir de ATLAS.Ti

Del mismo modo, dentro de los condicionantes para la permanecía de la actividad artesanal en Tepoztlán destaca el turismo, pero viéndose altamente determinado por la competencia comercial, especialmente entre los grupos artesanos y comerciantes. En este sentido, mientras que los impactos adjudicados a dicha actividad son percibidos principalmente por los propios artesanos y los promotores del turismo y el desarrollo local, desde el sector gubernamental suelen pasar desapercibidos. Así mismo, se presenta un porcentaje elevado de representatividad sociocultural desde el artesanado, reconociendo la existencia de identidad cultural implícita en las piezas artesanales y los procesos de producción. Finalmente, si bien el proceso de producción artesanal se desarrolla comúnmente dentro de los parámetros de la sustentabilidad, ésta no es un factor determinante para la permanencia de la artesanía en la dinámica turística desde la perspectiva de los agentes sociales (Tabla 2).

Tabla 2: Valores de Co-ocurrencia agentes sociales-condicionantes de la permanencia artesanal

\begin{tabular}{|c|c|c|c|c|c|c|}
\hline & Artesanos & Comerciantes & Funcionarios & $\begin{array}{c}\text { Prestadores } \\
\text { servicios }\end{array}$ & Promotores & TOTALES: \\
\hline Competencia & 17 & 11 & 5 & 8 & 5 & 46 \\
\hline $\begin{array}{c}\text { Impactos del } \\
\text { turismo }\end{array}$ & 16 & 5 & 3 & 9 & 12 & 45 \\
\hline $\begin{array}{c}\text { Representatividad } \\
\text { sociocultural }\end{array}$ & 20 & 5 & 5 & 9 & 1 & 40 \\
\hline Sustentabilidad & 4 & 2 & 8 & 7 & 1 & 22 \\
\hline Turismo & 31 & 7 & 8 & 14 & 9 & 69 \\
\hline
\end{tabular}

Fuente: Elaboración propia a partir de ATLAS.Ti

Finalmente, desde la perspectiva de los entrevistados, los factores determinantes para la permanencia artesanal (turismo y competencia comercial), están relacionados directamente con el valor comercial de la artesanía, condición que la reafirma como un producto esencialmente turístico en la cotidianidad tepozteca.

Sin embargo, los impactos producidos por el turismo al patrimonio artesanal también se ven correlacionados con el valor comercial; lo que se traduce en que, si bien el turismo fomenta el desarrollo económico y la producción artesanal en la localidad, también implica que los productores tengan que recurrir a cambios técnicos, estéticos y de materias primas 
con la finalidad de mantenerse rentables en un mercado altamente competitivo. Caso contrario ocurre con la representatividad sociocultural, que es atribuida principalmente al valor simbólico de la artesanía, manteniendo los signos y significados tradicionales aun cuando se adopten cambios técnicos en el proceso de elaboración (Tabla 3).

Tabla 3: Valores de Co-ocurrencia valores culturales-condicionantes de la permanencia artesanal

\begin{tabular}{|c|c|c|c|c|c|}
\hline & $\begin{array}{c}\text { Valor } \\
\text { comercial }\end{array}$ & $\begin{array}{c}\text { Valor } \\
\text { de uso }\end{array}$ & $\begin{array}{c}\text { Valor } \\
\text { estético }\end{array}$ & $\begin{array}{c}\text { Valor } \\
\text { simbólico }\end{array}$ & TOTALES: \\
\hline Competencia & 23 & 0 & 4 & 5 & 32 \\
\hline $\begin{array}{l}\text { Impactos del } \\
\text { turismo }\end{array}$ & 18 & 4 & 3 & 2 & 27 \\
\hline $\begin{array}{l}\text { Representatividad } \\
\text { sociocultural }\end{array}$ & 4 & 3 & 10 & 17 & 34 \\
\hline Sustentabilidad & 5 & 1 & 2 & 7 & 15 \\
\hline Turismo & 22 & 6 & 7 & 10 & 45 \\
\hline
\end{tabular}

Fuente: Elaboración propia a partir de ATLAS.Ti

\subsection{Agentes, vínculos e impactos percibidos del turismo en el patrimonio cultural artesanal}

Tal como se expresó en el apartado anterior, a nivel institucional, el Departamento de Desarrollo Económico se encarga de la promoción y difusión de la artesanía en Tepoztlán. En este sentido, desde la perspectiva gubernamental se promueven ferias artesanales, instaladas en temporadas altas en el primer cuadro del pueblo, así como la incentivación de la exportación artesanal a nivel estatal y nacional.

Así mismo, Tepoztlán se presenta como un escenario donde convergen artesanías de distintas regiones de la zona centro y sur del país. Los artesanos de fuera son fácilmente identificables con respecto a los comerciantes y revendedores por su vestimenta típica; además, por lo general, se dedican a la elaboración de textiles, destacando los provenientes de la zona mazahua del Estado de México, y regiones de Michoacán, Chiapas y Oaxaca.

Todos los años tenemos tres ferias artesanales, la intención es que, a través de la promoción, la gente pueda adquirir las artesanías producidas aquí, en Tepoztlán, pero si te das una vuelta por el tianguis, vas a encontrar cualquier tipo de artesanías, desde la oaxaqueña, vas a encontrar muchas cosas que se hacen en Michoacán, o sea, es un centro de distribución de artesanías de todo el pais (FL3).

Desde la percepción de los prestadores de servicio, se reconoce la relevancia de la artesanía dentro de la identidad tepozteca, por transmitir parte de la cultura local y estar presente dentro de sus mitos y festividades, motivo por el que expresan la importancia de la generación y comercio de artesanías locales, al elevar la identidad cultural de la población y permitir a los visitantes conocer más a fondo sobre la cotidianidad e idiosincrasia local. Sin embargo, se aprecia una baja ocupación artesanal en la zona turística respecto a los comerciantes, vendedores de souvenirs y otros tipos de servicios y productos turísticos. 
Hay mucha artesanía de otros lados, hay mucha ropa de Oaxaca, por ejemplo...la artesanía de fuera está distribuida por más partes de Tepoztlán, y la tepozteca como que la encuentras sólo en ciertos puntos, o cuando es la feria artesanal, aquí en el zócalo...Yo siento que es fácil de diferenciar la nuestra (la artesanía), porque es lo que nos identifica, soy parte de esto. (C4).

Así mismo, para el artesanado tepozteco, la producción obedece a dos fines primarios: el primero, referente al valor comercial que posiciona a la actividad artesanal como el medio de subsistencia para el productor, siendo comúnmente intercalado con otras actividades económicas como la agricultura o los servicios turísticos. Desde este primer esquema, se vislumbra en la actividad turística la principal fuente de ingresos, especialmente para aquellos artesanos pertenecientes a las comunidades aledañas de la zona centro de Tepoztlán, quienes encuentran en las temporadas altas su único acercamiento con el turista, mediante los tianguis de artesanías que se colocan al costado del quiosco de dos a tres veces al año.

Cuando es el fin de año, es la fecha cuando hay más ventas. En lo particular yo hago los palos de lluvia que le gustan mucho a la gente, porque es un instrumento que cuando lo escuchas bajar y subir, por el sonido del agua, como que se relaja uno; aunque también hacemos otras cositas, como vasos para lápices, tablitas para incienso, atrapasueños, y además las sonajas para los danzantes, y pues también teponaztles, entre otras cosas. (A4).

Por otra parte, se enfatiza la importancia del valor simbólico y estético de las piezas artesanales, al ser atribuidos a conocimientos heredados de generación en generación que se han ido perfeccionando mediante el trabajo constante de cada artesano, además de contener símbolos propios de su visión de las tradiciones y cotidianidad tepozteca. Esta condición es particularmente observable en los artesanos más experimentados de la localidad, y en aquellas nuevas generaciones pertenecientes a nichos familiares de tradición artesana.

Por ejemplo, algunas de las casitas que viste ayer, fueron hechas por mi nieto, cuando al turista se les queda viendo, les digo que esas fueron hechas por un niño de 11 años, y les llama más la atención... a veces, cuando las está haciendo, se lastima los dedos con la herramienta, pero yo le digo que eso es parte de la actividad, mire mis manos, a veces uno se encaja la herramienta mientras esta tallando, pero no pasa nada, así es como se va aprendiendo (A2).

Pues yo creo que todas las artesanías son representativas, no porque una tenga más tiempo significa que las demás son menos importantes, lo importante es el sentimiento y creatividad que le pone el artesano, si yo hago mis artesanías sólo pensando en vender más, pues no las haría con las mismas ganas que si pienso en hacerlo porque me gusta, el empeño del artesano es lo que las hace únicas (A1).

Del mismo modo, se reconoce la proliferación de artesanías de otras partes del país, las cuales, salvo por el pasaje de la catedral, se encuentran mejor ubicadas con respecto a las locales; además, la artesanía traída de otras localidades tiene un mayor posicionamiento en la compra por parte de los turistas al presentarse más variada. Pese a ello, el trato existente entre artesanos locales y externos es de cordialidad: si bien, no suelen darse vínculos de amistad 
muy estrechos entre ambos, los locales reconocen la importancia y esfuerzo de los artesanos de otras regiones y consideran que éstos fortalecen el atractivo e identidad local.

Es bueno que haya artesanos de otros lados, porque además venden otro tipo de artesanías, como las cajitas y los vestidos, o los tapetitos, y hasta le dan más realce a Tepoztlán, atraen más y eso es bueno, los que si nos perjudican de verdad son las bebidas alcohólicas (A3).

Análogamente, la condición de "centro artesanal" que se ha dado a las avenidas Revolución y del Tepozteco, permite dar mayor alcance a los artesanos locales al ubicarlos en zonas de acceso constante para el turista; sin embargo, también ha facilitado el incremento de puestos de revendedores que, sumados al mercado esotérico, saturan la imagen de pueblo tradicional y atomizan la derrama económica generada por el turista. Esta saturación de productos ha llevado a que muchos artesanos locales intercalen sus productos con artesanías traídas de otros lugares y souvenirs varios y, en el peor de los casos, abandonen la producción personal en aras de la reventa.

Según estimados de algunos entrevistados, la ocupación de artesanos en el mercado artesanal respecto a los comerciantes es de entre un 15 y $25 \%$. Aunque no se pudo constatar con datos duros el porcentaje exacto, el trabajo etnográfico y la visita constante a la zona, permitió corroborar que muchos puestos efectivamente pertenecen a comerciantes, tanto de artesanías como de objetos esotéricos, o en su defecto a artesanos que intercalan sus productos con souvenirs.

Un dato a recalcar respecto al posicionamiento de la artesanía externa es que, si bien posee una mayor proyección hacia el turista, son los comerciantes dedicados a la reventa quienes, por tener una mejor ubicación dentro de las zonas comerciales, acaparan este nicho de mercado, colocando al artesano externo en una situación similar o inferior a la del artesanado tepozteco, por la dificultad de acceder a puestos fijos o semifijos dentro de las zonas turísticas, obligándoles a recurrir al ambulantaje.

Es difícil, así como hay artesanos que están bien parados, hay muchos que deben estarle luchando por un puestecito, y así pasa también con los hoteleros y las fonditas; y también, muchos de los puestos que hay en las avenidas, no son de artesanos (PrD2).

De este modo, la saturación del mercado se vislumbra como uno de los principales impactos de la actividad turística en el patrimonio artesanal, al exigir al artesanado local y externo adaptarse a las demandas de un mercado cada vez más competitivo, sea mediante el abaratamiento de los productos; la intercalación entre la venta de artesanías propias, artesanías importadas y souvenirs; la venta directa a revendedores; el cambio de giro de artesano a comerciante; o bien, la innovación de los productos artesanales.

El pasajito de artesanías ni siquiera es de artesanos de aquí, de Tepoztlán.

Van al DF (Distrito Federal), las compran (las artesanías) y aquí le triplican el precio, y bueno, pues así funciona (PST1).

Está condición permea en las nuevas generaciones que vislumbran la actividad artesanal como poco rentable. 
A muchos ya no les interesa, prefieren irse a otros lugares o dedicarse a trabajar en un hotel, porque aquí no hay mucho de dónde escoger, y se van a Cuautla o al Distrito, aunque también hay otros que ven en la artesanía y el turismo una oportunidad (A1).

Bajo esta lógica, las artesanías tepoztecas más explotadas para la reventa son las casitas de pochote y los palos de lluvia, situación que se refleja en un cambio progresivo de las características y detalles de estas piezas con relación a las comerciadas por el mismo artesano, al presentarse menos trabajadas con el fin de abaratar los costos de producción y mantener su rentabilidad en el mercado turístico respecto a la competencia. En el caso de las casitas de pochote, es posible notar una considerable disminución en cuanto a la calidad del tallado y decorado, pasando comúnmente del esculpido general al tallado en bajo relieve.

Desde la perspectiva del comerciante, esta situación de abaratamiento y desplazamiento de la producción local se justifica por el valor añadido que requiere la importación de las piezas externas, la posibilidad de diversificar la oferta de productos artesanales en el mercado local y la demanda turística:

Se vende más la artesanía que traen de otros lados porque viene en mayor cantidad, variedad y modelos, aquí en Tepoztlán hay poquito...por otra parte, la artesanía local es más barata para la venta, porque la que viene de otros lados, se paga el transporte, el IVA, implica más gastos (C2).

Nosotros traemos las artesanías de obsidiana y resina de Teotihuacán, y pues lo que es de barro, nos lo traen personas de Guerrero. Lo más caro son los guerreros, los de allá que están pintados, y de lo que más se vende son las pirámides (de obsidiana) y los llaveros. Las casitas (de pochote) a veces también se venden un poco más, pero te las compran muy baratas, casi no les ganas (C5).

Otra consecuencia de la saturación de mercado es el regateo en las piezas artesanales, resultado directo de la flexibilidad de precios en los productos sustitutos, que obligan al artesano local a adecuarse a los precios dominantes, abaratando constantemente el trabajo producido en aras de la competitividad. De ello se refleja una fuerte desventaja en cuanto a costes y tiempos de producción, puesto que la labor artesanal pocas veces puede competir con la producción en serie en igualdad de condiciones sin sacrificar la calidad en el proceso. Finalmente, la insostenibilidad económica a la que son sometidos algunos artesanos en estas condiciones puede llevarlos a decantarse por la reventa de sus piezas, o el abandono de la actividad para dedicarse al comercio o los servicios turísticos, como medios de subsistencia.

Pues por lo mismo de que hay tantas cosas, a veces uno tiene que vender otras cositas como playeras o llaveritos, y a veces se venden más que las artesanías (A5).

Algunas personas antes se dedicaban a todo esto, pero ahora prefieren ir a traer su mercancía a otros lados, como que poco a poco se va perdiendo (A1).

Las artesanías de Tepoztlán tienen mucha tradición, pero siento que no se les da ese reconocimiento que se merecen, mucha de la misma gente de la 
comunidad sabe cuáles son, pero no su importancia, y es que tanto turismo hace que ya se vean más como un recuerdito. (PrD1).

Adicionalmente, se reconocen ciertos nichos de turistas que suelen recurrir a las prácticas de regateo, comúnmente turistas convencionales de procedencia nacional.

Quien regatea a veces es el mismo mexicano que quiere comprar todo barato y prefiere no comprar si no le rebajas, todavía que busca lo más barato quiere su descuento, imagínate, si una casita sencilla vale 15 o 20 pesos, ellos quieren que se la dejes en 10, o sea hasta la mitad, 10 pesos por el esfuerzo más la materia, si fueran cosas grandes como una lámpara de 200, 250, voy de acuerdo, pero no a todo se le puede rebajar (A5).

Referente a ello, aunque la mayoría de los artesanos señalan la improbabilidad de acceder al regateo, desde la observación se pudo constatar que, actualmente, es una práctica muy arraigada en la población, presumiblemente por el perfil dominante de turista impulsado desde el PPM. Sin embargo, desde el interior de la comunidad, y salvo por los promotores del desarrollo local, los agentes de la comunidad señalan que esta situación no obedece a los objetivos que el PPM plantea desde el discurso, sino a su ejecución en la realidad, al apostar por la masificación del destino y dejando de lado la preservación patrimonial intangible, que a la larga ha traído consigo perfiles de turista consumistas poco interesados en el trasfondo cultural y natural de la localidad, cuestión que permea en la interacción artesano-turista.

Es cuestión de imagen, de nada sirve que nosotros, los artesanos, o los del mercado, les enseñemos (al turista) las cosas que tenemos y hacemos, si a muchos lo que les interesa es subir al cerro y tomar. (A3).

El chiste es que cuando ya empiezas a vivir aquí, ya no te quieres juntar mucho con "la cosa turística" apoyada por el PPM, porque es falso todo eso, al inicio cuando no conoces y vienes, pues sí, pero más tarde te das cuenta de que es muy hueco. (PrD2).

En contraparte, desde las iniciativas del desarrollo local se aprecia una fuerte crítica al PPM tanto para el desarrollo de la actividad artesanal, como en la gestión turística en general.

El PPM se enfoca exclusivamente en la promoción del turismo, pero no analiza el tipo de turista que está atrayendo, ellos mismos, poco a poco están destruyendo el patrimonio de los tepoztecos (PrD2).

Del mismo modo, estos agentes vinculan las prácticas de regateo con el exceso de competencia en la zona turística promovido por la importación de artesanías a la comunidad y la proliferación de productos sustitutos con calidad de souvenirs (playeras, llaveros, figurillas, pulseras, entre otros), práctica que asocian con el abandono de la actividad artesanal.

Como hay muchas cosas, los artesanos, o los que antes eran artesanos, se dieron cuenta que al turista le gustaban más otro tipo de cosas, sobre todo subiendo al Tepozteco, hay muchas pirámides y calaveras y obsidianas, claro que también hay casitas y palos de lluvia, pero las figuras de barro o resina y las pirámides de obsidiana, es lo más visible. (PrD3). 
Todo lo que se vende de artesanía de hecho...vemos gente que viene del $D F$, vienen a comprar aquí, y dicen: "Ah, vamos a comprar algo de Tepoztlán", pero ellos (los comerciantes) lo van a comprar al DF (PrD2).

Por otra parte, el regateo en Tepoztlán posee también una arista cultural no necesariamente vinculada a los fines económicos, sino a una representación de agradecimiento hacia el comprador. Esta práctica, promovida desde el artesanado, es muy subjetiva y depende de diversos factores como el ánimo del artesano, la cantidad de piezas o dinero que haya invertido el visitante, o cuestiones de simpatía, entre otras.

Cuando compras más cosas, es lógico qué tiene uno que pedir un pequeño descuento, y con gusto se lo damos, pero no es lo habitual, solo a gente que vemos que nos está comprando mucho, de cierto modo ese descuentito es como decirles: "gracias por comprarme todas estas artesanías" (A4).

Así mismo, y pese a ser dos de las artesanías más propensas a la reventa, para el caso de las casitas de pochote y los palos de lluvia, las prácticas de regateo se ven directamente influenciadas por la calidad de la pieza y el prestigio del artesano: si bien, para los comerciantes es un recurso bastante habitual, en los puestos de artesanos consolidados se presenta como un evento esporádico, pues desde la percepción del comprador, el precio es acorde con el trabajo y calidad reflejados en las piezas; por ejemplo, en los detalles de las casitas de pochote, y los motivos, acabados y acústica en los palos de lluvia; por lo que se tiende a respetar el precio fijado.

Hay muchas cosas en una artesanía, no solo es un recuerdito como un llavero o un vasito, porque cuesta mucho hacerlas, algunas son más caras y no cualquiera te las paga, solo alguien que sabe del esfuerzo y la imaginación que hay en ellas (A1).

Por otra parte, diversos artesanos han recurrido a la innovación como herramienta para la permanencia de la artesanía local frente a los productos sustitutos. Este efecto es particularmente observable en la cerería, las piezas de bule y el injerto de aguacate, dada la versatilidad de diseños y formas con que pueden presentarse al mercado.

Así mismo, las casitas de pochote con estilos arquitectónicos más detallados mantienen una fuerte presencia en cuanto a su valor estético, simbólico y comercial. En este sentido, se observa que el artesanado tepozteco sabe aprovechar las formas de su materia prima, por lo que ésta no requiere una gran transformación sino de la habilidad en esculpido de cada uno.

Las espinas de pochote, o el injerto de aguacate, ya traen adentro lo que van a ser, sólo hace falta tallarlas un poco para darles forma, y ponerle de nuestra imaginación (A2).

Finalmente, algunos de los artesanos más consolidados, divisan la exportación como la principal alternativa para mantener la rentabilidad y permanencia de la actividad artesanal tepozteca. De ello que se promueva la generación de redes de exportación nacional e internacional, aunque actualmente sólo un pequeño grupo de artesanos tiene acceso a esta posibilidad tanto promovidos desde el campo gubernamental, como por iniciativa propia. 


\section{CONCLUSIONES}

Como se ha mencionado, y de acuerdo a los distintos agentes, las artesanías más representativas en la comunidad son las casitas de pochote, los palos de lluvia y el teponaztle, aunque la cerería y las artesanías de bule tienen mucha presencia en la zona comercial. Por otra parte, la producción del traje de chínelo es poco visible en la comunidad, aludiendo a que éstos son hechos por encargo, o bien para uso exclusivo del productor. De este modo, el traje de chínelo es una artesanía producida por y para la comunidad, aunque usualmente son adquiridos por chínelos de otras regiones de Morelos y el Estado de México, siendo el sombrero la pieza más solicitada.

Respecto a la inserción de la artesanía en la dinámica turística, destacan los valores estético y comercial con un fuerte dominio del arquetipo de la artesanía como producto turístico; si bien, para el artesano las piezas producidas poseen un alto valor de uso, estético, cultural y simbólico, en el caso de la comunidad en general, las autoridades y el turista, éstas representan más un bien de consumo para la generación de ingresos, convirtiéndose en un elemento complementario para el turismo, que se adquiere a modo de souvenir o recuerdo del viaje, situación que se refleja en la iconografía de algunas artesanías que tienden a grabar el nombre de la localidad con el objetivo de hacerlas más representativas en el imaginario del comprador.

Al interior de la comunidad existe una fuerte competencia de mercado con las artesanías provenientes de otras latitudes, así como con otros productos sustitutos que poseen la calidad de souvenirs (llaveros, playeras, pulseras, entre otros) lo que si bien, ha promovido la innovación artesanal de la comunidad, también ha llevado a los artesanos locales a intercalar sus piezas con productos de la manufactura.

Uno de los puntos a destacar es que, producto de la saturación comercial, el turismo efectivamente adquiere artesanías y otros productos con carácter de souvenirs durante su visita a Tepoztlán. Sin embargo, esta saturación dificulta al artesano local el poder mantenerse competitivo dentro del cuadro turístico, tanto en presencia como en ventas; ya que, desde la percepción de los mismos artesanos, los promotores del desarrollo local y los prestadores de servicios turísticos, la mayoría de los puestos establecidos en la zona corresponden a revendedores que, además de ofrecer precios más bajos, poseen un mayor abanico de productos, al intercalar artesanías locales compradas al mayoreo, con artesanías de otras regiones del país y souvenirs.

Esta condición ha hecho que algunos grupos artesanos comiencen a priorizar el valor económico de la artesanía por encima de su valor estético y cultural, convirtiéndose en proveedores de la reventa, además de buscar nuevas formas de producción más rápidas y baratas que, en detrimento de la calidad, se adhieran a los precios bajos del mercado y los gustos del turista convencional, llevando a la artesanía tepozteca, especialmente a la casita de pochote, a los derroteros del recuerdo de viaje más que al de patrimonio artesanal.

De este modo, se presenta una fuerte relación entre la generación de impactos en el patrimonio cultural artesanal y la competencia, teniendo su génesis en el valor comercial de la artesanía tepozteca respecto al de las artesanías de otras latitudes y el resto de souvenirs, 
condición que se transpola al valor estético y simbólico de las piezas, permeando en aspectos como el precio y la calidad, algo especialmente visible en aquellas destinadas a la reventa.

Por otra parte, pese a que a nivel general la artesanía no deja de ser un producto destinado al comercio con el fin primario de la subsistencia de los productores y vendedores, la mayoría de los artesanos señalan que el valor simbólico inserto en sus piezas es igual o mayor que su valor comercial, especialmente al considerar los años de experiencia, la calidad y esfuerzo que ponen en su oficio. En cuanto a los prestadores de servicio hay opiniones encontradas: aunque todos consideran a la artesanía como parte relevante de su patrimonio como tepoztecos, algunos anteponen su valor comercial por encima del cultural, mientras que otros destacan que es justamente ese valor cultural el que les da autenticidad y hace más atractivas a ojos del turista.

Finalmente, se reconoce a la actividad turística como un potenciador de cambios en los valores del patrimonio cultural artesanal, promoviendo la saturación de objetos artesanales y productos sustitutos que derivan en el detrimento estético y abaratamiento comercial de la artesanía local con el fin de mantenerse vigente dentro de un mercado cada vez más agresivo. Paradójicamente, el turismo se presenta a la vez como problema y solución para la economía del artesanado, pues, por una parte, el incremento de afluencia turística permite mantener la rentabilidad en ciertos nichos artesanos consolidados, a la vez que deconstruye los valores estéticos y simbólicos de aquellos aun no consolidados.

Por lo expuesto, se advierte la necesidad de la generación de redes de colaboración que se alejen del modelo de desarrollo económico centralizado promovido desde el PPM, en función de la capacidad de agencia de los distintos campos sociales, protagonistas de la actividad artesanal y turística en la comunidad de Tepoztlán, con la finalidad de promover la conservación, promoción y permanencia del patrimonio cultural artesanal desde iniciativas para el desarrollo local.

\section{REFERENCIAS BIBLIOGRÁFICAS}

Aguilar, M. (2015). Artesanía y Turismo. En: Rincón, N. (Ed.) Cultura y Turismo. Ecuador, Universidad del Azuay.

Alvarado, C. (2015). Conservación del patrimonio cultural en el Pueblo Mágico de Tepoztlán, Morelos (2001-2012). Territorios, 32, 15-33.

Arroyo, L. (2006). El impacto del turismo en las expresiones artesanales de Yucatán. Cuadernos de Patrimonio Cultural y Turismo. CONACULTA. 14, 111-118

Angrosino, M. (2012). Etnografía y observación participante en Investigación Cualitativa. Madrid: Morata

Campaña, V.; Molina, C. y Romero, A. (2015). Las potencialidades artesanales. Un análisis desde la perspectiva de desarrollo sostenible para su revalorización y empresarialidad turística. Retos Turísticos, 14 (1).

COESPO (2018). Indicadores demográficos de Morelos: 2018. Disponible en: http://coespo.morelos.gob.mx/sites/coespo.morelos.gob.mx/files/PDFs/enero proyecciones 2018 para_impresion.pdf 
Del Carpio-Ovando, P. (2012). Entre el textil y el ámbar: las funciones psicosociales del trabajo artesanal en artesanos tsotsiles de la ilusión, Chiapas, México. Athenea Digital, Revista de Pensamiento e Investigación Social 12, 185-198.

Del Carpio-Ovando, P. y Freitag, V. (2013). Motivos para seguir haciendo artesanías en México: convergencias y diferencias del contexto artesanal de Chiapas y Jalisco. Ra Ximhai, 9, (especial 1), 79-98.

Dittmer, K. (1960). Etnología general. México: Fondo de Cultura Económica.

Forstner, K. (2013). La artesanía como estrategia de desarrollo rural: el caso de los grupos de artesanas en la región de Puno (Perú). Cuadernos de Desarrollo Rural, 10 (72), 141-158.

Freitag, V. (2014). Entre arte y artesanía: elementos para pensar el oficio artesanal en la actualidad. El Artista, 11, 129-143.

Fuller, N. (2008). Turismo y Cultura. Entre el entusiasmo y el recelo. Perú: Fondo Editorial, Universidad Católica del Perú.

Garibay García, A. y Pilón Alonso, R. (2010). Una aproximación a la música prehispánica azteca. Antropología, Boletín oficial del Instituto Nacional de Antropología e Historia, 90, 3-6.

Govea, V., Vera, G., y Vargas, A. M. (2011). Etnografía: una mirada desde corpus teórico de la investigación cualitativa. Omnia, 17(2), 26 -39.

Hammersley, M. (2005). Etnografía. Métodos de investigación. Ed. Paidós. Barcelona, España. luva, C. y Ciliane, C. (2015). El souvenir artesanal y la promoción de la imagen del lugar turístico. Estudios y Perspectivas en Turismo. 24(2), 188-204.

Izaguirre Sotomayor, M. H. (2010). El turismo en el contexto de las sociedades complejas. Perú: Observatorio Turístico del Perú.

Jiménez, J.; Domínguez M. y Martínez, C. (2009). Estrategias y competitividad de los negocios de artesanía en México. Pensamiento y Gestión, 26, 165-190.

Martos Sánchez, E. (2009). La música en la Historia General de las Cosas de Nueva España de Fray Bernardino de Sahagún. Espiral, Cuadernos del profesorado, 2(3), 66-73.

Monterrubio Cordero, J. C. (2011). Turismo y cambio sociocultural. Una perspectiva conceptual. México: UAEMex, Plaza y Valdés.

Monterrubio Cordero, J. C. (2018). Impactos socioculturales del turismo. Dimensiones culturales, teóricas y empíricas. México: Triullas.

Morales, C. y Quintal, E. (1993). Cinco artesanías del oriente de Yucatán. México. ConacultaInah-Gobierno del estado de Yucatán.

Mordó, C. (2004). Creatividad artesanal: potencialidad para el desarrollo. Cuadernos de Patrimonio Cultural y Turismo CONACULTA. 4, 129-142.

Muecke, M. (2003). Sobre la evaluación de las etnografías. En: Morse, J. Asuntos críticos en los métodos de investigación cualitativa. Universidad de Antioquia.

Murillo, J., y Martínez, C. (2010). Investigación etnográfica. Métodos de Investigación Educativa. Ed. Especial, 3, 1-21.

Novelo, V. (2002). Ser indio, artista y artesano en México. Espiral, Estudios sobre Estado y Sociedad, 19 (25), 165,178.

Novelo, V. (2003). La Capacitación de Artesanos en México, una revisión. México: Plaza y Valdés.

Núñez, G. (2017). Condiciones en que subsiste el trabajo artesanal textil de Tenancingo, Estado de México. El Colegio Mexiquense. Toluca. 
Oliva Mendoza C. (2009). Artesanía. Universitas Humanística, 68, 287-296.

Popelka, C. A. (1991). Influence of tourism on handcraft evolution. Annals of Tourism Research, $18(3), 392-413$.

Rivera, M.; Alberti M.; Vázquez, V. y Mendoza, M. (2008). La artesanía como producción cultural susceptible de ser atractivo turístico en Santa Catarina del Monte, Texcoco. Convergencia, 15(46), 225-247.

Robles, B. (2011). La entrevista en profundidad: una técnica útil dentro del campo antropofísico. Cuicuilco, 18(52), 39-49.

Sales, F. (2013). Las artesanías en México Situación actual y retos. México: Centro de Estudios Sociales y de Opinión Pública. Cámara de Diputados / LXII Legislatura. México.

Turok, M. (1988). Como acercarse a la artesanía México. México: Consejo Nacional para la Cultura y las Artes, Plaza y Valdés.

Weaver, D. B. (2011). Contemporary tourism heritage as heritage tourism: Evidence from Las Vegas and Gold Coast. Annals of Tourism Research, 38 (1), 249-267.

Zorrilla, R. (2004). La artesanía: un producto cultural y comercial. Cuadernos de Patrimonio Cultural y Turismo CONACULTA. 4, 151-161 